\title{
A simple assessment of dyspnoea as a prognostic indicator in idiopathic pulmonary fibrosis
}

\author{
O. Nishiyama*, , H. Taniguchi*, Y. Kondoh*, T. Kimura*, K. Kato*, K. Kataoka*, \\ T. Ogawa", F. Watanabe ${ }^{\#}$ and S. Arizono"
}

ABSTRACT: The prognosis in idiopathic pulmonary fibrosis (IPF) is poor. No therapy has been shown to prolong survival. The objective of this study was to examine the prognostic significance of dyspnoea in daily living at baseline in IPF using a simple assessment tool.

93 consecutive patients with IPF, who had undergone evaluation at diagnosis, were included. The level of dyspnoea was assessed using the modified Medical Research Council (MRC) scale. The relationship between data at baseline and survival was examined.

A univariate Cox proportional-hazard model showed that forced vital capacity \% predicted (hazard ratio (HR) $0.965,95 \% \mathrm{Cl} 0.948-0.982 ; \mathrm{p}<0.0001$ ), diffusing capacity of the lung for carbon monoxide \% predicted (HR 0.978, 95\% Cl 0.963-0.993; $p=0.0041$ ), baseline arterial oxygen tension (HR 0.963, 95\% Cl 0.938-0.989; $p=0.0060$ ) and modified MRC score (HR 2.402, 95\% Cl 1.4953.858; $p=0.0003$ ) were significantly predictive of survival. All variables of the 6-min walk test, including walk distance (HR 0.995, 95\% Cl 0.992-0.998; $p=0.0020$ ), the lowest arterial oxygen saturation measured by pulse oximetry $\left(\mathrm{Sp}, \mathrm{O}_{2}\right)(\mathrm{HR} 0.944,95 \% \mathrm{Cl} 0.918-0.972 ; \mathrm{p}<0.0001)$ and the Borg scale (HR 1.285, 95\% Cl 1.091-1.514; $p=0.0027$ ), were also significant. With stepwise, multivariate Cox proportional analysis, the modified MRC score (HR 2.181, 95\% Cl 1.333-3.568; $\mathrm{p}=0.0019$ ) and the lowest $\mathrm{Sp}, \mathrm{O}_{2}$ during the 6-min walk test (HR 0.952, 95\% Cl 0.924-0.981; $p=0.0014$ ) were the most significant.

Dyspnoea in daily living, assessed with the modified MRC scale at baseline, provides additional prognostic information for patients with IPF.

KEYWORDS: Dyspnoea, idiopathic pulmonary fibrosis, mortality

diopathic pulmonary fibrosis (IPF) is the most common entity of idiopathic interstitial pneumonia with a poor survival rate, which has been reported to be $\sim 3$ yrs $[1,2]$. No therapy has been proven to be beneficial to prognosis [1].

Recent studies have demonstrated that several demographic, physiological, radiographic, and histopathological features predict survival in IPF [3-9]. Moreover, serial changes in some physiological parameters were also suggested to be associated with survival [9-13].

However, the prognostic significance of dyspnoea in daily living has not yet been fully elucidated, though it is a main symptom of IPF. In some reported methods for assessing dyspnoea in daily living, the modified Medical Research Council (MRC) scale [14, 15] is used, especially in chronic obstructive pulmonary disease (COPD) [16]. However, the prognostic value of dyspnoea assessed with the modified MRC scale is still unclear in IPF. The purpose of the present study was to examine the prognostic significance of dyspnoea in daily living in IPF using the modified MRC scale.

\section{METHODS}

\section{Subjects}

93 consecutive patients with IPF, who had undergone evaluation at diagnosis, as is the general practice in Tosei General Hospital (Aichi, Japan), were included in this study, covering the period April 2000-July 2005. The diagnosis of IPF was made in accordance with the American Thoracic Society (ATS)/European Respiratory Society (ERS) statement [1], using the following major criteria: 1) exclusion of other known causes of interstitial lung disease; 2) abnormal pulmonary function with restriction and impaired gas exchange; 3) bibasilar reticular abnormalities on
AFFILIATIONS

*Dept of Respiratory Medicine and Allergy,

\#Dept of Rehabilitation, Tose General Hospital, Seto, Aichi, and "Dept of Respiratory Medicine and Allergology, Kinki University School of Medicine, Osaka-sayama, Osaka, Japan.

CORRESPONDENCE

H. Taniguchi

Dept of Respiratory Medicine and Allergy

Tosei General Hospital

160 Nishioiwake-cho

Seto

Aichi 489-8642

Japan

E-mail: taniguchi@tosei.or.jp

Received:

Sept 282009

Accepted after revision:

April 072010

First published online:

April 222010 
high-resolution computed tomography; and 4) transbronchial lung biopsy or bronchoalveolar lavage showing no features to support an alternative diagnosis. Minor criteria included: 1) age $>50 \mathrm{yrs} ; 2$ ) insidious onset of otherwise unexplained dyspnoea; 3) duration of illness $>3$ months; and 4) bibasilar inspiratory crackles. All of the major and at least three of the four minor criteria had to be satisfied. For those with a surgical lung biospy specimen showing usual interstitial pneumonia (UIP), only the major criteria were considered relevant. Surgical lung biopsies were performed in 18 (19.4\%) patients, and the pathological diagnosis of UIP was also based on the consensus statement [1]. Patients were excluded if they had any of the following: obvious COPD, collagen vascular disease, active coronary artery disease or other severe comorbid illness. All patients enrolled in the study were newly diagnosed with IPF and had not yet received any treatment, such as corticosteroids or cytotoxic agents. Patients who could not perform a 6-min walk test were excluded. Patients who were receiving long-term oxygen therapy at the time of enrolment were also excluded. The present study was based on a retrospective analysis of clinically indicated studies of patients with IPF performed in our hospital. The informed consent requirement was waived for the study. Approval for the use of these data was provided by our Institutional Review Board (Tosei General Hospital).

\section{Pulmonary function tests}

All patients underwent spirometry (CHESTAC-55V; Chest, Tokyo, Japan), according to the method described in the ATS 1995 update [17]. Single-breath diffusing capacity of the lung for carbon monoxide (DL,CO) was also measured (CHESTAC$55 \mathrm{~V})$. The values for forced vital capacity (FVC), forced expiratory volume in $1 \mathrm{~s}$ (FEV1) and DL,CO were related to \% predicted values [18].

\section{6-min walk test}

The 6-min walk test was conducted in all patients who participated in the study, according to the ATS statement [19]. Briefly, all patients were tested under standardised conditions by trained technicians. Baseline blood pressure, heart rate and oxygen saturation were measured. Patients were instructed to walk as far as possible in $6 \mathrm{~min}$. The distance the patients could walk was recorded. Oxygen saturation was also measured by pulse oximetry at rest for $5 \mathrm{~min}$ prior to and immediately after the test. All patients underwent the tests twice to minimise the training effects. Patients were asked to rate their dyspnoea at the end of the test, using the modified Borg scale, by selecting a number from $0-10$, with 0 being no appreciable dyspnoea and 10 being maximal sustainable dyspnoea [20].

\section{Assessment of dyspnoea in daily living}

The modified MRC scale was used to evaluate dyspnoea in daily living. The modified MRC scale includes five grades (04) of various physiological activities that provoke dyspnoea $[14,15]$. After the patients had read the descriptive phrases, they selected the number that best corresponded to their level of dyspnoea in daily living. The descriptions were as follows: 0 , not troubled with breathlessness except with strenuous exercise; 1 , troubled by shortness of breath when hurrying on the level or walking up a slight hill; 2, walks slower than people of the same age on the level because of breathlessness or has to stop for breath when walking at own pace on the level; 3, stops for breath after walking $\sim 100$ yards or after a few minutes on the level; and 4, too breathless to leave the house, or breathless when dressing or undressing [14, 15].

\section{Assessment of survival}

Survival was assessed up to December 7, 2008. Deaths and the cause of death were identified by reviewing the hospital records. Because most of the patients had been visiting our hospital once a month and were admitted when their condition became worse, documentation of their survival could be obtained. The survival time was calculated as the period from diagnosis to their death. In cases in which a patient was still alive, the survival time was calculated as the period from diagnosis to the last day the patient visited our hospital during the study period, but he or she was treated as a censored case in the analysis. For some patients who had moved to other hospitals and we could obtain the date of their death, their actual survival time was used in the analysis. The day of diagnosis was defined as the day a patient underwent the first examination in our hospital.

\section{Statistical analysis}

Continuous variables are summarised as mean \pm SD. Categorical variables are summarised by frequency. The dyspnoea level in daily activity, assessed using the modified MRC score, and breathlessness in the 6-min walk test, assessed using the Borg scale, were analysed as continuous variables. Univariate Cox's proportional-hazard models were used to examine the association of selected variables with survival. The stepwise multivariate Cox's proportional-hazards model was then used among variables that were revealed to be significant in the univariate model, to select more significant variables. Briefly, variables that were significant $(\mathrm{p}<0.05)$ in the univariate analysis were included in the multivariate model but forwardly eliminated based on selection criteria of $<0.05$. To avoid multicollinearity, only one of the highly correlated variables (Pearson's correlation coefficient $\geqslant 0.6$ ) was to be entered in the multivariate model, if present. Kaplan-Meier survival estimates were compared using the log-rank test across the modified MRC dyspnoea score and the lowest $\mathrm{O}_{2}$ saturation at the 6-min walk test. All tests were performed at a significance level of $\mathrm{p}<0.05$. Analyses were performed using the PASW statistical package, version 18 (SPSS Japan Inc., Tokyo, Japan).

\section{RESULTS}

93 patients were included in the study, consisting of 81 males and 12 females. The mean $\pm \mathrm{SD}$ age at diagnosis was $66.3 \pm 8.1$ yrs. Their clinical and physiological data are summarised in table 1 . The mean observation period was $40.6 \pm 25.8$ months. In this observation period, of $49(52.7 \%)$ patients, $18(19.4 \%)$ died due to respiratory failure, $13(14.0 \%)$ due to acute exacerbation of IPF, 5 (5.4\%) due to pneumonia, 5 $(5.4 \%)$ due to a cancer, $4(4.3 \%)$ due to other known causes and $4(4.3 \%)$ due to unknown causes. 45 patients died in our hospital, so the exact dates of their death could be obtained. We could also obtain the dates of death for four patients who died in other hospitals, although the reasons for their death were not known. Distribution of baseline-modified MRC 
dyspnoea scores and baseline results of the 6-min walk test are shown in table 1.

The results of univariate Cox proportional hazard model are shown in table 2. FVC \% predicted (hazard ratio (HR) 0.965, 95\% CI 0.948-0.982; p<0.0001), DL,CO \% predicted (HR 0.978, 95\% CI 0.963-0.993; $\mathrm{p}=0.0041)$, baseline arterial oxygen tension $\left(\mathrm{Pa}, \mathrm{O}_{2}\right)$ (HR 0.963, 95\% CI 0.938-0.989; $\left.\mathrm{p}=0.0060\right)$, and modified MRC score (HR 2.402, 95\% CI 1.495-3.858; $\mathrm{p}=0.0003$ ) were revealed to be significantly predictive of survival. All variables of the 6-min walk test including the walk distance (HR 0.995, 95\% CI 0.992-0.998; $\mathrm{p}=0.0020)$, the lowest arterial oxygen saturation measured by pulse oximetry $\left(\mathrm{Sp}_{\mathrm{p}} \mathrm{O}_{2}\right)(\mathrm{HR} 0.944,95 \%$ CI 0.918-0.972; $\mathrm{p}<0.0001$ ) and the Borg scale (HR 1.285, 95\% CI $1.091-1.514 ; \mathrm{p}=0.0027)$ were also significant. There were no highly correlated (correlation coefficient $\geqslant 0.6$ ) variables

\begin{tabular}{|c|c|c|}
\hline TABLE 1 & \multicolumn{2}{|c|}{$\begin{array}{l}\text { Baseline characteristics and physiology of } \\
\text { patients\# }\end{array}$} \\
\hline \multirow{2}{*}{\multicolumn{3}{|c|}{$\begin{array}{l}\text { Age yrs } \\
\text { Sex }\end{array}$}} \\
\hline & & \\
\hline \multicolumn{2}{|l|}{ Male } & 81 \\
\hline \multicolumn{2}{|l|}{ Female } & 12 \\
\hline \multicolumn{2}{|l|}{ Height $\mathbf{c m}$} & $160.8 \pm 8.0$ \\
\hline \multicolumn{2}{|c|}{ Body weight kg } & $60.4 \pm 11.6$ \\
\hline \multicolumn{2}{|l|}{$\mathrm{BMI} \mathbf{k g} \cdot \mathrm{m}^{-2}$} & $23.3 \pm 3.5$ \\
\hline \multicolumn{3}{|c|}{ Smoking status } \\
\hline \multicolumn{2}{|l|}{ Current } & 15 \\
\hline \multicolumn{2}{|l|}{ Former } & 59 \\
\hline \multicolumn{2}{|l|}{ Never } & 19 \\
\hline \multicolumn{3}{|c|}{ Baseline pulmonary function testing } \\
\hline \multicolumn{2}{|l|}{ FVC L } & $2.37 \pm 0.73$ \\
\hline \multicolumn{2}{|c|}{ FVC \% pred } & $75.0 \pm 20.1$ \\
\hline \multicolumn{2}{|l|}{ FEV 1 L } & $1.93 \pm 0.57$ \\
\hline \multicolumn{2}{|c|}{ FEV $1 \%$ pred } & $85.4 \pm 22.1$ \\
\hline \multicolumn{2}{|c|}{$\mathrm{DL}, \mathrm{CO} \mathrm{mL} \cdot \mathrm{min}^{-1} \cdot \mathrm{mmHg}^{-1}$} & $9.19 \pm 3.92$ \\
\hline \multicolumn{2}{|c|}{$D \mathrm{~L}, \mathrm{CO} \%$ pred } & $56.3 \pm 20.6$ \\
\hline \multicolumn{3}{|c|}{ Baseline arterial blood gas values } \\
\hline \multicolumn{2}{|c|}{$\mathrm{Pa}, \mathrm{O}_{2} \mathrm{mmHg}$} & $81.0 \pm 11.9$ \\
\hline \multicolumn{2}{|c|}{$\mathrm{Pa}, \mathrm{CO}_{2} \mathrm{mmHg}$} & $39.8 \pm 5.3$ \\
\hline \multicolumn{2}{|l|}{$\mathrm{pH}$} & $7.42 \pm 0.03$ \\
\hline \multicolumn{3}{|c|}{ MMRC score } \\
\hline \multicolumn{2}{|l|}{0} & 11 \\
\hline \multicolumn{2}{|l|}{1} & 41 \\
\hline \multicolumn{2}{|l|}{2} & 38 \\
\hline \multicolumn{2}{|l|}{3} & 3 \\
\hline \multicolumn{2}{|l|}{4} & 0 \\
\hline \multicolumn{3}{|c|}{ 6-min walk test at baseline } \\
\hline \multicolumn{2}{|c|}{ Walk distance $\mathrm{m}$} & $516 \pm 96.8$ \\
\hline \multicolumn{2}{|c|}{ Lowest $\mathrm{Sp}, \mathrm{O}_{2} \%$} & $82.7 \pm 9.5$ \\
\hline Borg score & & $4.0 \pm 2.1$ \\
\hline
\end{tabular}

Data are presented as mean \pm SD or $n$. BMl: body mass index; FVC: forced vital capacity; \% pred: \% predicted; FEV1: forced expiratory volume in $1 \mathrm{~s} ; D \mathrm{~L}, \mathrm{CO}$ : diffusing capacity of the lung for carbon monoxide; $\mathrm{Pa}_{\mathrm{a}} \mathrm{O}_{2}$ : arterial oxygen tension; $\mathrm{Pa}_{1} \mathrm{CO}_{2}$ : arterial carbon dioxide tension; MMRC: modified Medical Research Council; $\mathrm{Sp}_{1} \mathrm{O}_{2}$ : arterial oxygen saturation measured by pulse oximetry. ${ }^{\#}: \mathrm{n}=93$ except for $\mathrm{DL}, \mathrm{CO}(\mathrm{n}=90), \mathrm{Pa} \mathrm{O}_{2}(\mathrm{n}=90), \mathrm{Pa}_{\mathrm{a}} \mathrm{CO}_{2}(\mathrm{n}=90), \mathrm{pH}$ $(n=90)$ and 6 -min walk test variables $(n=92)$. among them. In stepwise multivariate Cox proportional analysis, modified MRC score (HR 2.181, 95\% CI 1.333-3.568; $\mathrm{p}=0.0019$ ) and the lowest $\mathrm{Sp}, \mathrm{O}_{2}$ (HR 0.952, 95\% CI 0.924-0.981; $\mathrm{p}=0.0014$ ) were selected as most significant (table 3). In normal (not stepwise) multivariate Cox proportional analysis, including modified MRC score, the lowest $\mathrm{Sp}, \mathrm{O}_{2}$ and walk distance at the 6-min walk test, and DL,CO \% predicted, as independent variables, the results were as follows: modified MRC score (HR $1.903,95 \%$ CI 1.117-3.239; $\mathrm{p}=0.0178$ ) lowest $S_{\mathrm{p}, \mathrm{O}_{2}}(\mathrm{HR} 0.951$, 95\% CI 0.913-0.990; $\mathrm{p}=0.0146$ ) walk distance (HR 0.999, 95\% CI $0.995-1.002 ; \mathrm{p}=0.4105)$ and $\mathrm{DL}, \mathrm{CO} \%$ predicted (HR 1.000, 95\% CI $0.980-1.020 ; \mathrm{p}=0.9839)$.

Kaplan-Meier survival curves based on the modified MRC score and presence of desaturation (lowest $\mathrm{Sp}, \mathrm{O}_{2}<88 \%$ ) during the 6-min walk test are shown in figure 1 . The median survival estimates for patients with a modified MRC level of $0-1,2$ and 3 were 66.7, 30.9 and 10.2 months, respectively. The median survival estimates for subjects with and without desaturation were 41.0 and 62.9 months, respectively.

\section{DISCUSSION}

We confirmed that dyspnoea in daily living, assessed using the modified MRC scale, as well as the lowest $S_{\mathrm{p}}, \mathrm{O}_{2}$ at 6 -min walk test, were the strongest predictors of survival in patients with IPF. Dyspnoea is one of the most fundamental and debilitating symptoms of patients with IPF. The results in the present study indicate that evaluation of the dyspnoea level when diagnosing patients with IPF is important to predict their survival. Moreover, it was revealed that, no matter how well-preserved or bad the pulmonary physiology, the survival of a more dyspnoeic patient is shorter.

\begin{tabular}{lcc} 
TABLE 2 & $\begin{array}{l}\text { Results of univariate Cox proportional hazard } \\
\text { model }^{\#}\end{array}$ & p-value \\
\hline Variables & HR (95\% Cl) & \\
\hline & $1.027(0.987-1.069)$ & 0.1915 \\
Age & & \\
Smoking status & & \\
$\quad$ Current & $0.818(0.338-1.984)$ & 0.6573 \\
$\quad$ Former & $0.959(0.475-1.936)$ & 0.9069 \\
BMI & $0.977(0.891-1.071)$ & 0.6233 \\
FVC \% pred & $0.965(0.948-0.982)$ & $<0.0001$ \\
DL,Co \% pred & $0.978(0.963-0.993)$ & 0.0041 \\
Pa, $\mathbf{O}_{2}$ mmHg & $0.963(0.938-0.989)$ & 0.0060 \\
MMRC score & $2.402(1.495-3.858)$ & 0.0003 \\
Walk distance m & $0.995(0.992-0.998)$ & 0.0020 \\
Lowest Sp, $\mathbf{O}_{\mathbf{2}} \%$ & $0.944(0.918-0.972)$ & $<0.0001$ \\
Borg score & $1.285(1.091-1.514)$ & 0.0027 \\
\hline
\end{tabular}

The walk distance, lowest $\mathrm{Sp}, \mathrm{O}_{2}$, and Borg are variables of 6-min walk test. HR hazard ratio; BMI: body mass index; FVC: forced vital capacity; \% pred: \% predicted; DL,CO: diffusing capacity of the lung for carbon monoxide; $\mathrm{Pa}_{1} \mathrm{O}_{2}$ : partial pressure of oxygen; MMRC: modified Medical Reasearch Council; $\mathrm{Sp}, \mathrm{O}_{2}$ : arterial oxygen saturation measured by pulse oximetry \#: $\mathrm{n}=93$ except for $\mathrm{DL}, \mathrm{CO}(\mathrm{n}=90)$ and $\mathrm{Pa}, \mathrm{O}_{2}(\mathrm{n}=90)$. never-smokers. 


\begin{tabular}{|c|c|c|}
\hline TABLE 3 & \multicolumn{2}{|c|}{$\begin{array}{l}\text { Results of stepwise multivariate Cox proportional } \\
\text { hazard model }\end{array}$} \\
\hline Variables & HR $(95 \% \mathrm{Cl})$ & p-value \\
\hline MMRC score & $2.181(1.333-3.568)$ & 0.0019 \\
\hline Lowest $\mathrm{Sp}, \mathrm{O}_{2} \%$ & $0.952(0.924-0.981)$ & 0.0014 \\
\hline \multicolumn{3}{|c|}{$\begin{array}{l}\text { Variables that were significant in univariate analysis (table } 2 \text { ) were included in } \\
\text { the analysis. Lowest arterial oxygen saturation measured by pulse oximetry } \\
\left(\mathrm{Sp}, \mathrm{O}_{2}\right) \text { is a } 6 \text {-min walk test variable. MMRC: modified Medical Research } \\
\text { Council. }{ }^{*}: \mathrm{n}=87 \text {, because patients for whom all data were available were } \\
\text { included in the analysis; } 46 \text { of these patients }(52.9 \%) \text { died during the } \\
\text { observation period. }\end{array}$} \\
\hline
\end{tabular}

Many previous studies have shown that several physiological parameters predict survival in patients with IPF [4, 7]. FVC, total lung capacity (TLC), $\mathrm{FEV} 1, \mathrm{DL}, \mathrm{CO}$, and $\mathrm{Pa}_{1} \mathrm{O}_{2}$ at diagnosis, as well as longitudinal changes in these physiological parameters, were shown to predict survival [10-13]. Furthermore, parameters obtained from the 6-min walk test, such as walk distance and presence of desaturation during the test were recently shown to be prognostic in IPF $[8,9]$. A recent study showed that low oxygen uptake during cardiopulmonary exercise testing also predicts worse survival [21]. In the current study, $\mathrm{FVC}, \mathrm{DL}, \mathrm{CO}, \mathrm{Pa}_{\mathrm{a}} \mathrm{O}_{2}$, and variables from the 6-min walk test including walk distance, the lowest $\mathrm{Sp}, \mathrm{O}_{2}$, and the Borg scale, were revealed to be significant predictors of survival in the univariate model. These results are consistent with previous reports [4, 7-13]. In addition to predicting parameters demonstrated in earlier studies, it is an important finding of the present study that dyspnoea in daily living was a stronger prognostic parameter than most physiological markers at diagnosis. It indicates that dyspnoea in daily living should be carefully evaluated and included in the assessment of patients with IPF, even though such assessments have not focused on like physiological parameters to date.

In previous COPD-related studies, dyspnoea in daily living has already been recognised as an important prognostic factor. In a 5-yr, prospective, multicentre trial of 227 patients with COPD, survival was not significantly linked to COPD staging based on FEV1, whereas dyspnoea measured by the MRC scale predicted their survival [22]. Celli et al. [16] developed a multidimensional grading system to predict survival of patients with COPD, called the BODE (body mass index, degree of airflow obstruction, dyspnoea, exercise capacity) index. The BODE score was reportedly better than pulmonary function data at predicting the mortality risk in COPD. Dyspnoea in daily living is one of the important components of the BODE index. Thus, dyspnoea has already been recognised as an important factor in predicting survival and has been included in COPD evaluations. IPF is a disease that leads to a number of morbidities or sequelae, such as dyspnoea and exercise limitation, like COPD. Multidimensional evaluations that include dyspnoea are also becoming important in IPF. Actually, dyspnoea impairs the life of patients with IPF; it measurably worsens over time [23] and appears to be one driver of health-related quality of life [24]. Therefore, evaluating
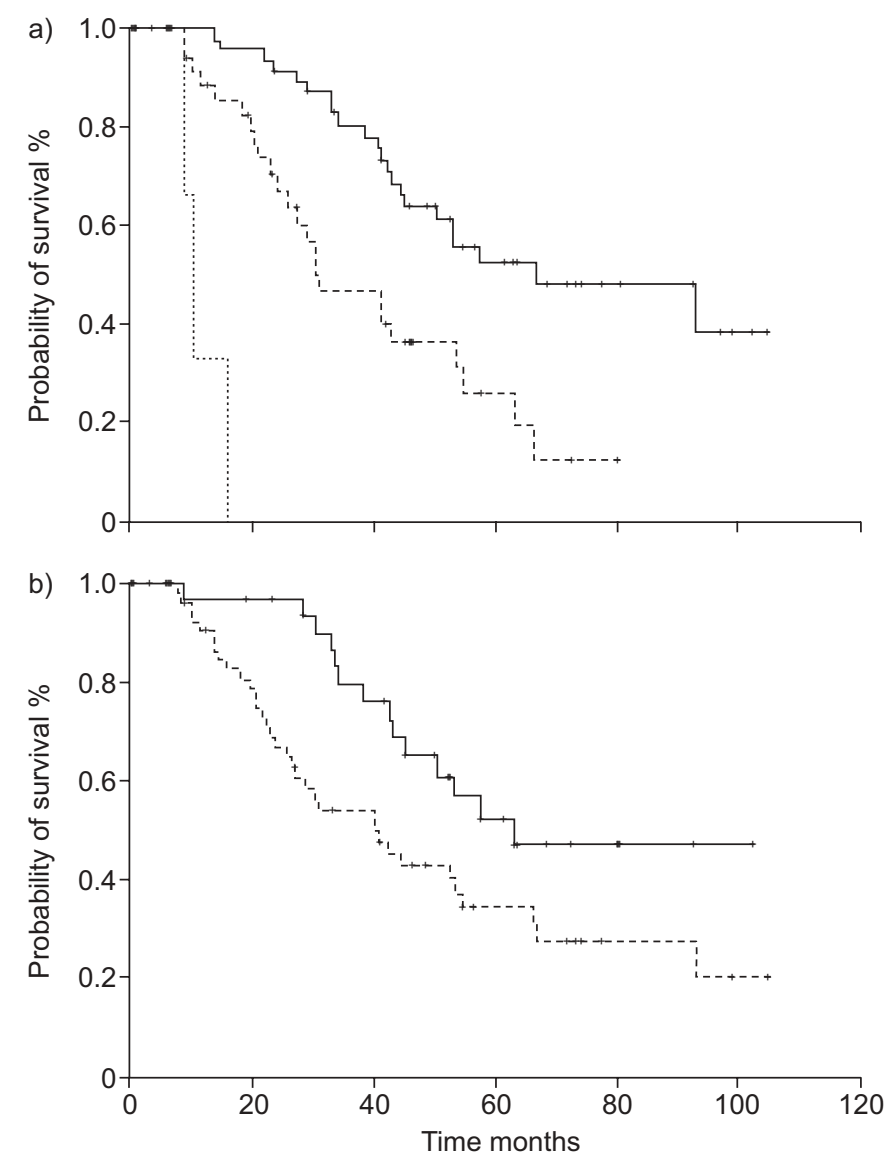

FIGURE 1. Kaplan-Meier survival curves according to a) the modified Medical Research Council (MMRC) score (-: MMRC 0-1; ---: MMRC 2; …...... MMRC 3) $(p<0.0001)$ and $b)$ the lowest arterial oxygen saturation measured by pulse oximetry $\left(\mathrm{Sp}, \mathrm{O}_{2}\right)$ during the 6-min walk test $\left(-: \mathrm{Sp}, \mathrm{O}_{2} \geqslant 88 \%\right.$; ---: $\left.\mathrm{Sp}, \mathrm{O}_{2}<88 \%\right)(\mathrm{p}=0.023)$. Survival curves were compared with log-rank statistic. +: censored.

dyspnoea in daily living should be recognised as important in general practice as well.

There is some confusion in the evaluation of dyspnoea. In terms of the modified MRC score, two types of scale have been used. One has five grades for rating the level of dyspnoea [14, $15]$ and the other has six grades [25]. A scoring system grading 21 levels of dyspnoea was used in multistep scores (CRP score; clinical, radiological and physiological score) in terms of IPF [4]. The baseline dyspnoea scale has also often been used in previous studies related to COPD; it uses five grades $(0-4)$ for each of the categories, functional impairment, magnitude of task, and magnitude of effort (0-12 for total score) [26]. The University of California San Diego Shortness of Breath Questionnaire has also sometimes been used [27]. This questionnaire comprises 24 items that assess dyspnoea over the preceding week. However, these scores are too cumbersome to apply in clinical practice. Although the Borg scale, which lists phrases increasing subjective intensity of breathlessness from 0 to 10, is often used, it is for assessing dyspnoea on exertion [28], not in daily living. We used the modified MRC scale with four grades of dyspnoea because it is easier to rate and is also used in the BODE index developed for COPD. A complicated method for grading is not advisable for 
practical use. Our data suggest that a simple evaluation of the dyspnoea level can predict mortality in patients with IPF, without the need for complex calculations.

The association of dyspnoea with survival in IPF has been reported in some previous studies. TURNER-WARWICK et al. [29] showed a significant relationship between dyspnoea assessed with a five-point (0-4) scale and survival in cryptogenic fibrosing alveolitis, although the details of the assessing method were not mentioned. However, in that study, the diagnosis was not based on the current guidelines, and it is highly possible that patients with nonspecific interstitial pneumonia (NSIP), whose survival must have been better than that of patients with IPF, were included at that time. Moreover, $\sim 30 \%$ of patients had connective tissue disease. In contrast, the strength of our study is that patients were limited to those with IPF. Patients with connective tissue disease were excluded, and patients with NSIP were also excluded because the diagnosis was made according to the current consensus statement. KING et al. [4] reported that a dyspnoea scale which consisted of 21 points (0-20) was significantly related to survival of patients with IPF. However, a 21-point scale is quite inconvenient to rate and not suitable for clinical practice. Only one report has demonstrated the efficacy of the MRC dyspnoea score for predicting survival in IPF; it consists of a relatively small series of patients with IPF [30]. Moreover, the MRC score used in that study had six grades for dyspnoea. In contrast, we chose the modified MRC score, which consists of five grades of dyspnoea because it is quite popular and has often been used in COPD. The present study is the first report, to our knowledge, to demonstrate that the five-point modified MRC scale predicts survival in IPF. Another novel point about the current study is that we included variables from a 6-min walk test, which has been proven to be important in predicting survival of patients with IPF. Then, the modified MRC score and the lowest $S_{\mathrm{p}}, \mathrm{O}_{2}$ at a 6-min walk test were then selected as significant. We confirmed the importance of dyspnoea in daily living in 93 patients. Interestingly, it was more predictive of survival than physiological measurements. Thus, the dyspnoea level should also be assessed and included in further research on IPF. In both research and clinical practice, the five-point modified MRC is quite useful because of its power to predict survival and its simplicity.

The lowest $\mathrm{Sp}, \mathrm{O}_{2}$ during the 6-min walk test was found to be another significant predictor for survival in the present study. It is already evident that the presence of desaturation is related to a severe prognosis in some previous studies [10]. We adopted the level of desaturation as a continuous variable, not as a categorised variable divided by the presence of desaturation. Thus, the present study demonstrated that severe desaturation leads to a worse prognosis.

The strengths of this study include the relatively large sample size and the relatively high mortality; more than half of all the patients died, making the results of analysis reliable. The limitations of this study are as follows. First, there is a the lack of serial changes in physiological parameters in the analysis. Longitudinal changes in physiology reportedly predict survival [10-13]. Another result could be obtained if serial changes in physiological parameters were included in the analysis. However, serial changes in physiology can not be measured at diagnosis. Predicting survival from parameters at diagnosis is indeed crucial. Secondly, our results might have been different if baseline haemodynamics had been included in the analysis, but unfortunately these data were not available, because it is reported that pulmonary hypertension significantly impacts survival in IPF [31, 32]. Thirdly, the results are not necessarily applicable to patients with supplemental oxygen, because patients with supplemental oxygen were excluded from the study. Finally, the retrospective study design is a limitation. Collecting additional prospective data is warranted to confirm our findings.

In all probability, survival of patients with IPF will be prolonged if the dyspnoea level in daily activity improves. No pharmacological therapy has been shown to improve dyspnoea or to prolong life in IPF. However, pulmonary rehabilitation that consists of exercise training reportedly improves dyspnoea [33], but this claim is not indisputable [34]. Further research must determine whether pulmonary rehabilitation improves dyspnoea and, consequently, prolongs survival in IPF. The effect of oxygen therapy should also be examined. If oxygen ameliorates the level of dyspnoea in daily living and prevents desaturation in patients with IPF, longterm oxygen therapy might prolong survival. To test this hypothesis, further prospective study is needed.

In summary, the present study demonstrates that dyspnoea in daily living, assessed with the modified MRC score and the lowest $\mathrm{Sp}, \mathrm{O}_{2}$ during the 6-min walk test, provides stronger prognostic prediction than other physiological parameters in patients with IPF. This assessment tool for dyspnoea is beneficial because of its power to predict survival and its simplicity.

\section{SUPPORT STATEMENT}

This work was supported by a grant-in-aid for interstitial lung diseases from the Japanese Ministry of Health and Welfare.

\section{STATEMENT OF INTEREST}

None declared.

\section{REFERENCES}

1 American Thoracic Society. Idiopathic pulmonary fibrosis: diagnosis and treatment. International consensus statement. American Thoracic Society (ATS) and the European Respiratory Society (ERS). Am J Respir Crit Care Med 2000; 161: 646-664.

2 Bjoraker JA, Ryu JH, Edwin MK, et al. Prognostic significance of histopathologic subsets in idiopathic pulmonary fibrosis. Am J Respir Crit Care Med 1998; 157: 199-203.

3 Flaherty KR, Toews GB, Travis WD, et al. Clinical significance of histological classification of idiopathic interstitial pneumonia. Eur Respir J 2002; 19: 275-283.

4 King TE Jr, Tooze JA, Schwarz MI, et al. Predicting survival in idiopathic pulmonary fibrosis: scoring system and survival model. Am J Respir Crit Care Med 2001; 164: 1171-1181.

5 Gay SE, Kazerooni EA, Toews GB, et al. Idiopathic pulmonary fibrosis: predicting response to therapy and survival. Am J Respir Crit Care Med 1998; 157: 1063-1072.

6 Nicholson AG, Fulford LG, Colby TV, et al. The relationship between individual histologic features and disease progression in idiopathic pulmonary fibrosis. Am J Respir Crit Care Med 2002; 166: 173-177. 
7 Xaubet A, Agusti C, Luburich P, et al. Pulmonary function tests and CT scan in the management of idiopathic pulmonary fibrosis. Am J Respir Crit Care Med 1998; 158: 431-436.

8 Lederer DJ, Arcasoy SM, Wilt JS, et al. Six-minute-walk distance predicts waiting list survival in idiopathic pulmonary fibrosis. Am J Respir Crit Care Med 2006; 174: 659-664.

9 Lama VN, Flaherty KR, Toews GB, et al. Prognostic value of desaturation during a 6-minute walk test in idiopathic interstitial pneumonia. Am J Respir Crit Care Med 2003; 168: 1084-1090.

10 Flaherty KR, Andrei AC, Murray S, et al. Idiopathic pulmonary fibrosis: prognostic value of change in physiology and six-minutewalk test. Am J Respir Crit Care Med 2006; 174: 803-809.

11 Latsi PI, du Bois RM, Nicholson AG, et al. Fibrotic idiopathic interstitial pneumonia: the prognostic value of longitudinal functional trends. Am J Respir Crit Care Med 2003; 168: 531-537.

12 Collard HR, King TE Jr, Bartelson BB, et al. Changes in clinical and physiologic variables predict survival in idiopathic pulmonary fibrosis. Am J Respir Crit Care Med 2003; 168: 538-542.

13 Flaherty KR, Mumford JA, Murrays S, et al. Prognostic implications of physiologic and radiographic changes in idiopathic interstitial pneumonia. Am J Respir Crit Care Med 2003; 168: 543-548.

14 Mahler DA, Rosiello RA, Harver A, et al. Comparison of clinical dyspnea ratings and psychophysical measurements of respiratory sensation in obstructive disease. Am Rev Respir Dis 1987; 135: 1229-1233.

15 Mahler DA, Wells CK. Evaluation of clinical methods for rating dyspnea. Chest 1988; 93: 580-586.

16 Celli BR, Cote CG, Marin JM, et al. The body-mass index, airflow obstruction, dyspnea, and exercise capacity index in chronic obstructive pulmonary disease. N Engl J Med 2004; 350: 1005-1012.

17 Medical Section of the American Lung Association. Standardization of spirometry: 1994 update. Am J Respir Crit Care Med 1995; 152: 1107-1136.

18 Hanamoto S, Ohsuji T, Tsuyaguchi I, et al. [Prediction formulas for pulmonary function tests expressed in linear and exponential form for healthy Japanese adults.] Nihon Kyobu Shikkan Gakkai Zasshi 1992; 30: 2051-2060.

19 American Thoracic Society. ATS statement: guidelines for sixminute walk test. Am J Respir Crit Care Med 2002; 166: 111-117.

20 Borg GA. Psychophysical basis of perceived exertion. Med Sci Sports Exerc 1982; 14: 377-381.
21 Fell CD, Liu LX, Motika C, et al. The prognostic value of cardiopulmonary exercise testing in idiopathic pulmonary fibrosis. Am J Respir Crit Care Med 2009; 179: 402-407.

22 Nishimura K, Izumi $\mathrm{T}$, Tsukino $\mathrm{M}$, et al. Dyspnea is better predictor of 5-year survival than airway obstruction in patients with COPD. Chest 2002; 121: 1434-1440.

23 Martibez FJ, Safrin S, Weycker D, et al. The clinical course of patients with idiopathic pulmonary fibrosis. Ann Intern Med 2005; 142: 963-967.

24 Nishiyama $\mathrm{O}$, Taniguchi $\mathrm{H}$, Kondoh $\mathrm{Y}$, et al. Health-related quality of life in patients with idiopathic pulmonary fibrosis. What is the main contributing factor? Respir Med 2005; 99: 408-414.

25 Eltayara L, Becklake MR, Volta CA, et al. Relationship between chronic dyspnea and expiratory flow limitation in patients with chronic obstructive pulmonary disease. Am J Respir Crit Care Med 1996; 154: 1726-1734.

26 Mahler DA, Weinberg DH, Wells CK, et al. The measurement of dyspnea. Contents, interobserver agreement, and physiologic correlates of two new clinical indexes. Chest 1984; 85: 751-758.

27 Eakin EG, Resnikoff PM, Prewitt LM, et al. Validation of a new dyspnea measure. Chest 1998; 113: 619-624.

28 Borg GA. Psychophysical basis of perceived exertion. Med Sci Sports Exerc 1982; 14: 377-381.

29 Turner-Warwick M, Burrows B, Johnson A. Cryptogenic fibrosing alveolitis: clinical features and their influence on survival. Thorax 1980; 35: 171-180.

30 Manali ED, Stathopoulos GT, Kollintza A, et al. The Medical Research Council chronic dyspnea score predicts the survival of patients with idiopathic pulmonary fibrosis. Respir Med 2008; 102: 586-592.

31 Lettieri CJ, Nathan SD, Barnett SD, et al. Prevalence and outcomes of pulmonary arterial hypertension in advanced idiopathic pulmonary fibrosis. Chest 2006; 129: 746-752.

32 Hamada K, Nagai S, Tanaka S, et al. Significance of pulmonary arterial pressure and diffusion capacity of the lung as prognosticator in patients with idiopathic pulmonary fibrosis. Chest 2007; 131: 650-656.

33 Holland AE, Hill CJ, Conron M, et al. Short term improvement in exercise capacity and symptoms following exercise training in interstitial lung disease. Thorax 2008; 63: 549-554.

34 Nishiyama O, Kondoh Y, Kimura T, et al. Effects of pulmonary rehabilitation in patients with idiopathic pulmonary fibrosis. Respirology 2008; 13: 394-399. 